\title{
New work: New motivation? A comprehensive literature review on the impact of workplace technologies
}

\author{
Yvonne Schmid $^{1}$ (D) Michael Dowling ${ }^{1}$
}

Received: 1 July 2020 / Accepted: 21 October 2020 / Published online: 4 November 2020

(c) The Author(s) 2020

\begin{abstract}
The role of work and the characteristics of the workplace have changed greatly in recent decades. Today, new technologies enable an almost seamless interaction between machines and humans and allow teams in different countries and time zones to collaborate effectively. In this paper, we focus on the question of how job motivation is affected by technologies in the changing workplace. First, we review the state of research on job motivation and examine challenges in light of current technology trends and predicted developments for the workplace of the future. Job motivation is a well-documented construct connected to several company-relevant performance outcomes. However, our comprehensive literature review reveals a fragmented picture, with several disciplines addressing the topic from various points of view. We identify the four following schools of thought on workplace technologies and motivation: Technology as 1 . background music, 2. hygiene factor, 3. motivator, and 4. influencer of mediators. While some scholars neglect technology in their considerations, others describe complex frameworks. This lack of unity reveals a further need for research. We suggest further research to develop holistic frameworks including moderators and to collect empirical data on the complex interactions between technology and job motivation.
\end{abstract}

Keywords Workplace technology · Workplace design · Employee motivation • Comprehensive literature review

JEL Classification $\mathrm{O} 330 \cdot$ Y 80

Yvonne Schmid

Yvonne.Schmid@UR.de

1 Department of Innovation and Technology Management, University of Regensburg,

Universitätsstr. 31, 93053 Regensburg, Germany 


\section{Introduction}

New technologies are emerging at an ever-accelerating pace. Not only are voice-recognition systems, household robots, or new digital services, e.g., Amazon's Alexa, having an impact on our private lives, but work environments are also changing significantly (Brynjolfsson and McAfee 2016; Cascio and Montealegre 2016; Leopold et al. 2016; Oldham and Hackman 2010). Technologies in the workplace, such as mobile devices, the Internet of Things, or AI-based applications, shape modern work processes and spaces.

Adopting new technologies and designing workplaces requires high investments and educated managerial decisions to integrate them into the companies' strategies (Chan et al. 2007; Kampschroer and Heerwagen 2005; Schmid 2020; Vischer 2007). Meanwhile, labor shortages and other challenges in recruiting and retention management are affecting human resources (HR) and strategic management processes (Cascio and Montealegre 2016). The much sought-after high skilled workers demand modern and appropriate resources to work with. According to the Future Workforce Study 2016, “[n]early half of American Millennials (42\%) say they'd likely quit a job if workplace tech didn't meet their standards" (Dell Technologies and Intel 2016). As a result, it is necessary to understand the individual needs and perceptions to implement workplace technologies in an effective and strategic manner (Parker and Ohly 2008). These challenges raise the question of how technology in the workplace affects employees on an individual level.

Prior research focuses mainly on how workplace technology influences wellbeing, productivity, comfort, satisfaction, and territoriality and identity/belonging (Kim 2014; Vischer 2008). Most of these concepts are linked to employee motivation (Miller et al. 2001). The scientific discussion is dominated by works that focus on the changes in work content caused by technological change that lead to motivating aspects in the workplace. Regarding technology itself, technology demotivating employees is oftentimes a popular notion. However, according to an Eventboard survey among 1000 professionals, 38\% claim they are motivated by innovative tech tools (Eventboard.io 2016).

Motivation is a widely accepted construct that leads to, among other things, better performance, lower fluctuation, lower accident rates (Hackman and Oldham 1976; Kanfer and Ackerman 2004; Maxwell 2008; Seeck and Diehl 2016), and job satisfaction (Taylor and Westover 2011). Brown (2012) even declares that "[m]otivation is one of the most critical elements within any kind of workplace." Thus, employee motivation becomes a crucial strategic asset from a managerial point of view. With this aspect in mind, it might be useful to rephrase our initial question as:

\section{How does workplace technology affect employee motivation?}

There are many publications with practical recommendations on how to successfully design workplaces and integrate upcoming technology to keep employees motivated and productive (Barrett 2015; Caramela 2018; Hartog et al. 2017; Prince 2017). As most of these publications are merely based on anecdotal insights and the scientific field is fragmented, rigorous academic research is needed (KaranikaMurray and Michaelides 2015; Oldham and Hackman 2010; Parker 2014). 
In this paper, we investigate existing research and assess whether current models and theories are suitable for explaining how workplace technologies influence employee motivation. This paper departs from prior studies by focusing on motivational theories and studies from the point of view of changing workspaces in the digital era in a structured and comprehensive manner.

In the following sections, we will describe the theoretical background of the topics at hand before introducing our approach based on the Comprehensive Literature Review as proposed by Onwuegbuzie and Frels (2016). After analyzing these results in depth, we will cluster them into the four schools of thought which are characterized by the nature of the technological influence on motivation: Technology as 1 . background music, 2. hygiene factor, 3. motivator, and 4. influencer of mediators. We will then present implications for research and management and our conclusion.

\section{Theoretical background}

\subsection{Workplace technology}

There is no uniform understanding in the literature of what terms denote the technologies used in the workplace. For this reason, we coin the term workplace technologies to provide a common understanding for the following literature review. "Technology is a system-level variable or cluster of variables, which can be conceptualized as the techniques used by an organization or its subunits to transform inputs into outputs." (Billings et al. 1977: 319) Following this definition, technology in the context of organizations focuses on the value creation process in general. While this is also the case for workplace technologies, these can be divided into two categories. On the one hand, the "technical tools [are] needed to get work done, such as workstations, computers, or mobile devices." (Schmid 2020) On the other hand, technologies incorporated in workplace design are a necessary situational aspect to support value creation, such as office design, room layout, or furniture. Accordingly, we define workplace technologies as the technologies that surround the employee and are needed to get the job done. Thus, we call the act of implementing such technologies and therefore shaping the physical work environment 'workplace design'. While these definitions provide a good starting point to assess the topic, we will evaluate the terms used in the literature more closely in our analysis in Sect. 4.2.

\subsection{Employee motivation}

Diefendorff and Chandler (2011) provide a comprehensive yet concise understanding of motivation, which we also base this work on: "Motivation is often described as an unobservable force that directs, energizes, and sustains behavior over time and across changing circumstances." While other authors provide different definitions, they all have in common that motivation is a construct or invisible driver, which induces behavior. Research in motivation and thus the origin of behavior in the workplace already began a century ago with the conception of humans contradicting 
the technocentric worldview that had been predominant at the beginning of the twentieth century (Komlosy 2014). One of the most cited research projects on workers from that time is the Hawthorne Studies (Landsberger 1968; Mayo 1949). These experiments observed how changes in the working conditions influence worker productivity. Researchers interpreted the results as mechanisms inherent in the individual and group structures affecting employee motivation.

These insights led others to shift the focus of their research from the physical aspects to the emergence of a more person-centered view on motivation in the following decades (Kim 2014; Veitch 2018). Groundbreaking theories like Maslow's hierarchy of needs or Herzberg's Two Factor Theory as well as various process theories focusing on the cognitive mechanisms leading to behavior emerged (Herzberg et al. 2017/1959; Maslow and Stephens 2000).

Herzberg's Dual-Factor Theory is one of the most frequently cited theories in management research. Using the critical incidents method, he identified context factors as a hygiene factor, which leads to dissatisfaction when absent or unfavorably designed. However, sufficient workplace technology or other context factors may not lead to motivation (Herzberg et al. 2017/1959). While still one of the major theories taking external factors and employee motivation into account, it is often criticized for not being replicable with other approaches. Scholars suspect a methodological artefact (Hackman and Oldham 1976). However, the notion of adequate context factors merely preventing demotivation led to another direction for research.

In the following years, many researchers examined the impact of work conditions on health and how the work environment can influence humans negatively. For example, the Job-Demand-Control-Model and its successor, the Job-DemandsResources-Model, explain the development of exhaustion based on an unfavorable working environment (=job demand) (Demerouti and Bakker 2011; Veitch 2018). Depending on the level of demands or resources available, a job can be perceived as straining/stressful or motivating (Karasek 1979; Parker et al. 2017a). Physical and technological resources are part of this approach, yet the allocation explains negative results like stress rather than motivational aspects (Demerouti and Bakker 2011).

To consider individual differences in motivation and work design perceptions, Hackman and Oldham developed the Job Characteristics Model (JCM) based on a study with the Job Diagnostics Survey. Technology is not a central part of the model (Hackman and Oldham 1976).

The Self-Determination Theory (SDT), which was developed a decade after the identification of the Job Characteristics, focuses on the person and conceptualizes intrinsic motivation achieved by addressing the needs autonomy, relatedness, and competence (Deci and Ryan 1985; van den Broeck et al. 2016). Prior content theories have already focused on needs or need categories. The underlying assumption in all cases is that a person is motivated to show a certain behavior in pursuit of satisfying these needs (Maslow and Stephens 2000).

Yet another perspective on the topic highlights the emotional component of feeling motivated. Mihaly Csikszentmihalyi coined the term "flow" in 1990 to describe a mental state in which a person is fully focused on a task. Flow occurs depending on individual readiness, tasks, and external circumstances (Csikszentmihalyi 2010). 


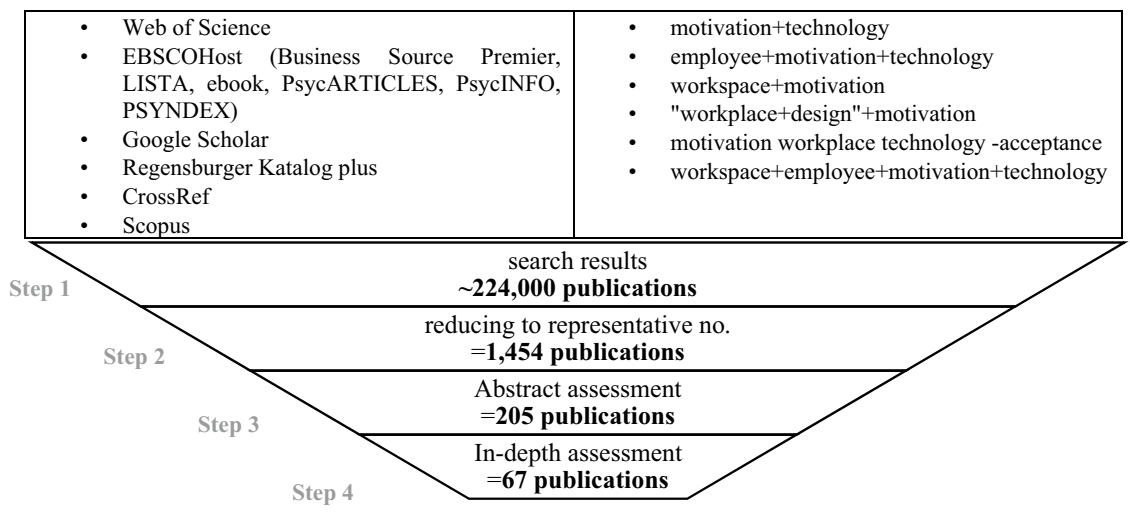

Fig. 1 Search strings and filtering methods produced 67 results for a comprehensive literature review (own illustration)

Another wave of research that occurred in the 1990s and 2000s attempted to integrate existing research and create a broader perspective as each of the motivation theories and models focuses on a different aspect to study the concept of motivation (Diefendorff and Chandler 2011; Humphrey et al. 2007; Parker et al. 2017a). In this period, empirical data provided new insights - particularly on the properties of extrinsic incentives. The results indicate ambiguous effects of material rewards on intrinsic motivation in so-called interesting or creative tasks (Amabile et al. 1986; Becker and Steele 1995; Deci et al. 1999; Heckhausen and Heckhausen 2010). For innovative behavior in particular, this connection plays a critical role in improving work results (Seeck and Diehl 2016).

\section{Literature review}

Due to the constant growth in publications in this research domain during the past decades, the existing literature is plentiful. To cope with the amount of research and achieve a comprehensive overview, we chose a structured approach. In response to calls for methodological rigor in management literature reviews (Bouncken et al. 2015; Fisch and Block 2018; Tranfield et al. 2003), we provide a structured review of motivation research publications and how they consider workplace technologies. Onwuegbuzie and Frels (2016) suggest that the Comprehensive Literature Review offers the opportunity to assess large volumes of publications in a transparent manner. To identify the key publications on the topic, we followed the four steps as outlined below. Figure 1 presents an overview of the details of each step.

1. Search: To capture a broad range of results, we placed no prior restrictions on the definition of motivation or workplace-related influences. We chose general search terms accordingly. Search strings in different scientific databases with combinations of search terms related to the topic provided more than 200,000 results.

2. Filter: We filtered these results by assessing a representative number of abstracts (Krejcie and Morgan 1970, as cited in Onwuegbuzie and Frels 
2016) — resulting in 1454 abstracts. Here, we relied on the databases' results sorted by relevance.

3. Selection: Depending on the search engine, we found hundreds of results unrelated to the initial question. Many of these publications used the term "motivation" to describe the relevance of the topic. Others were closer to the topic at hand, yet unfit for shedding light on the current question. A recurring notion, for example, is the use of "workspace" to describe the radius of a robot arm. Other publications, some of which were works on the Technology Acceptance Model and its variations, referred to the mechanisms of how people can be motivated to use certain technologies at work. As the guiding criterion in this step was to select publications that cover aspects of employee motivation as defined above, we excluded those search results, which resulted in 205 useful publications.

4. Evaluation: We evaluated the remaining publications in depth to find out whether they addressed motivational theory in general and, specifically, the influence of workplace technology as defined above. During this assessment, we find that that a large part of motivation research has only marginally considered workplace technologies in their research. The authors mention 'workplace attributes' (Karanika-Murray and Michaelides 2015; Taylor and Westover 2011), 'workplaces' (Wong et al. 2008) or other situational aspects including technological elements. However, workplace technology is not at the center of attention but can instead be perceived as "background music" within these approaches. Thus, we excluded those publications. We also assessed reference lists to add further relevant publications (backward snowballing). Finally, we identified 67 publications dealing with job motivation and workplace technologies.

\section{Analysis of the literature sample}

In this section, we will analyze the 67 publications resulting from the above-mentioned procedure. To do so, we use an integrative approach including a systematic descriptive analysis to identify trends and gaps in this research area. Following a descriptive analysis on origin, publication date, and quality of the results, we will assess the contents in detail by mapping the perspectives on motivation and the theories applied as well as the different external factors. Subsequently, different perceptions of the relationship between workplace technologies and motivation are reviewed.

\subsection{Descriptive analysis of the sample}

From the 67 publications, the earliest works are from Denise M. Rousseau and Oldham and Brass applying the 'Job Characteristics Model' by Hackman/Oldham from the 1970 s. ${ }^{1}$ While office automation was a popular topic in the 1980 s, works by

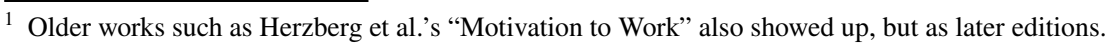


6

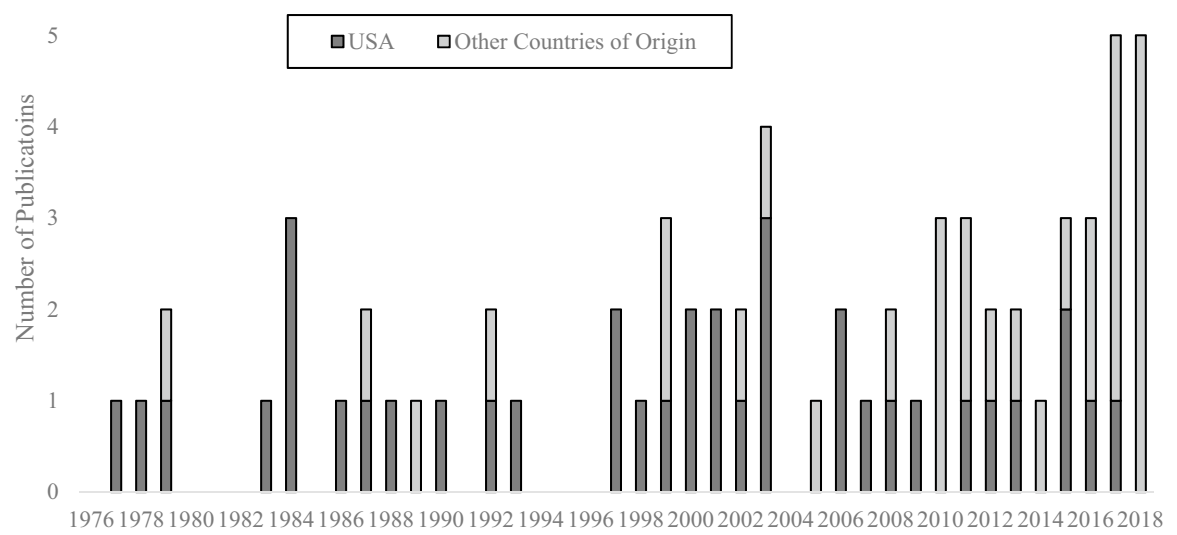

Fig. 2 First Authors' origin over time shows rising numbers of non-US-based publications $(n=67)$

Teresa M. Amabile on creativity and intrinsic motivation had an undeniable effect on motivation research in the 1990s. Most of the results though are from the 2000s and later, where the diversity of disciplines and origin increased.

Over time, the authors' country of origin shifted away from the United States. Overall, the focus still lies on Northern America, with more than half of the authors working there, but widens to include other regions such as Europe, Southeast Asia, and Australia_-particularly after 2010 (see Fig. 2). These results reflect the growing interest in motivating workplace design in developed countries.

Most publications come from rather traditional fields like psychology and (HR) management as well as from more recent disciplines like technology and facility management. Depending on the field, the perspective on the topic differs. While psychological and pedagogic publications have a stronger focus on the cognitive and affective processes, authors with a technological background tend to initially build on motivation theories but then focus on technological characteristics and details (Liu et al. 2018; Perryer et al. 2016).

Since we considered different databases, about one quarter of the results are not scientific journal articles, but books (reference books, textbooks, anthologies) or grey literature such as reports or comments. To determine the quality of the scientific articles, we consulted the most recent editions of the VHB Jourqual published by the German Association of Business Professors, the AJG from the British Chartered Association of Business Schools, and the JCR Impact Factor provided by Web of Science. The type and quality of the relevant results are listed in Table 1.

To capture the diversity of the sources, we included all quality levels in our analysis; however, we consider the kind of publications when interpreting the results in the discussion.

The majority of publications (almost half of them) present a literature review, none of them using a structured approach. Eleven authors develop a new theory or framework, while others review the current state of research with a comprehensive 


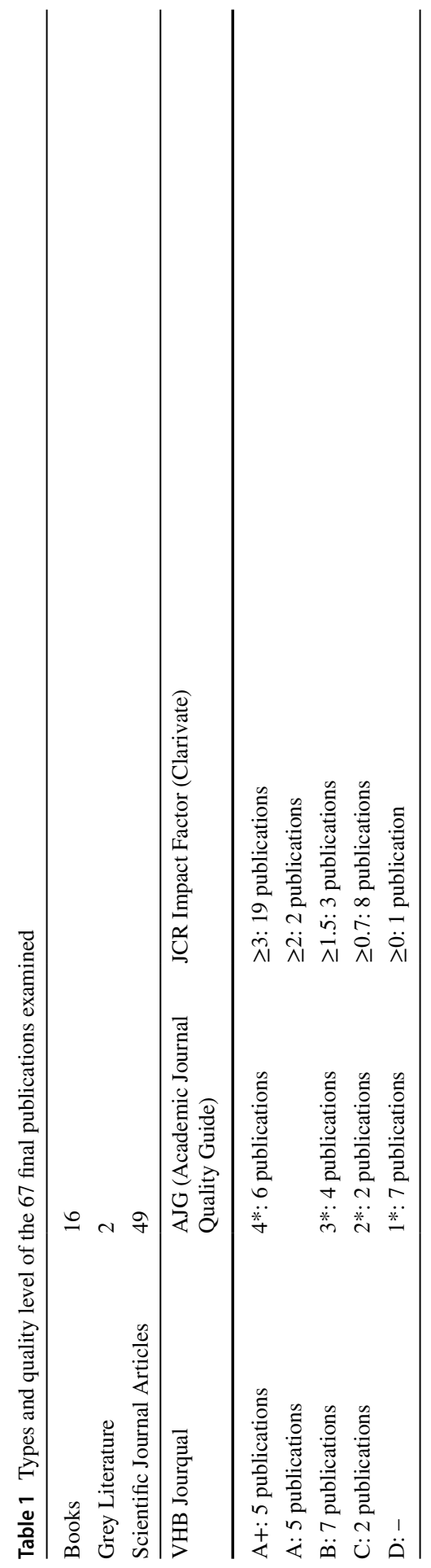


Table 2 Applied methodologies in research on motivating workspace design $(n=67)$

\begin{tabular}{ll}
\hline Number of publications & Method \\
\hline 20 & Conceptual \\
11 & Literature Review \\
& Theory Building \\
5 & Quantitative Methods \\
4 & Descriptive Methods \\
9 & Variance Analyses \\
4 & Regression Analyses \\
3 & Factor Analyses \\
3 & Qualitative Methods \\
8 & Mixed Methods \\
\hline
\end{tabular}

overview of the situation. Especially worth mentioning is "Work Design Influences: A Synthesis of Multi-Level Factors that Affect the Design of Work" by Parker et al. (2017b), as the collection and number of the sources is impressive.

Another third of the results contains quantitative analyses-with questionnaires as the primary method of choice. Depending on the underlying theory, the Job Diagnostics Survey (JDS), Work Preference Inventory (WPI), Work Design Questionnaire (WDQ), or a combination of items from these and other questionnaires were used. Other data collection methods include experiments or diary surveys; the critical incidents-method is a specific approach that is mostly used when reproducing data based on Herzberg's Two Factor Model (Knight and Westbrook 2015). Few authors opted for a qualitative or mixed approach including thematic analyses of interviews and diary entries. Table 2 provides an overview.

Having described the quantity and structure of our 67 search results, we turn to the content of the publications in the following sections. To ensure a systematic process, we first outline the different types of technologies influencing job motivation mentioned in the literature. We will then show how the researchers conceptualized the relationship between those influences and job motivation.

\subsection{Types of workplace technologies}

Different authors provide different understandings of the influencing technologiesthe terms used vary greatly. Table 3 provides an overview of these terms.

Many authors work with rather general terms to include physical environmental aspects. Expressions like situation (Heckhausen and Heckhausen 2010), job/work context (Herzberg et al. 2017/1959; Humphrey et al. 2007), physical environment (Demerouti and Bakker 2011; Mitchell 1997; Mitchell and Daniels 2003), physical working conditions (Knight and Westbrook 2015; Osteraker 1999; Rožman et al. 2017), work/office environment (Amdan et al. 2016; Barford and Hester 2011; Brenner 1999), or workplace design (Hancock 2009) are used. These terms 


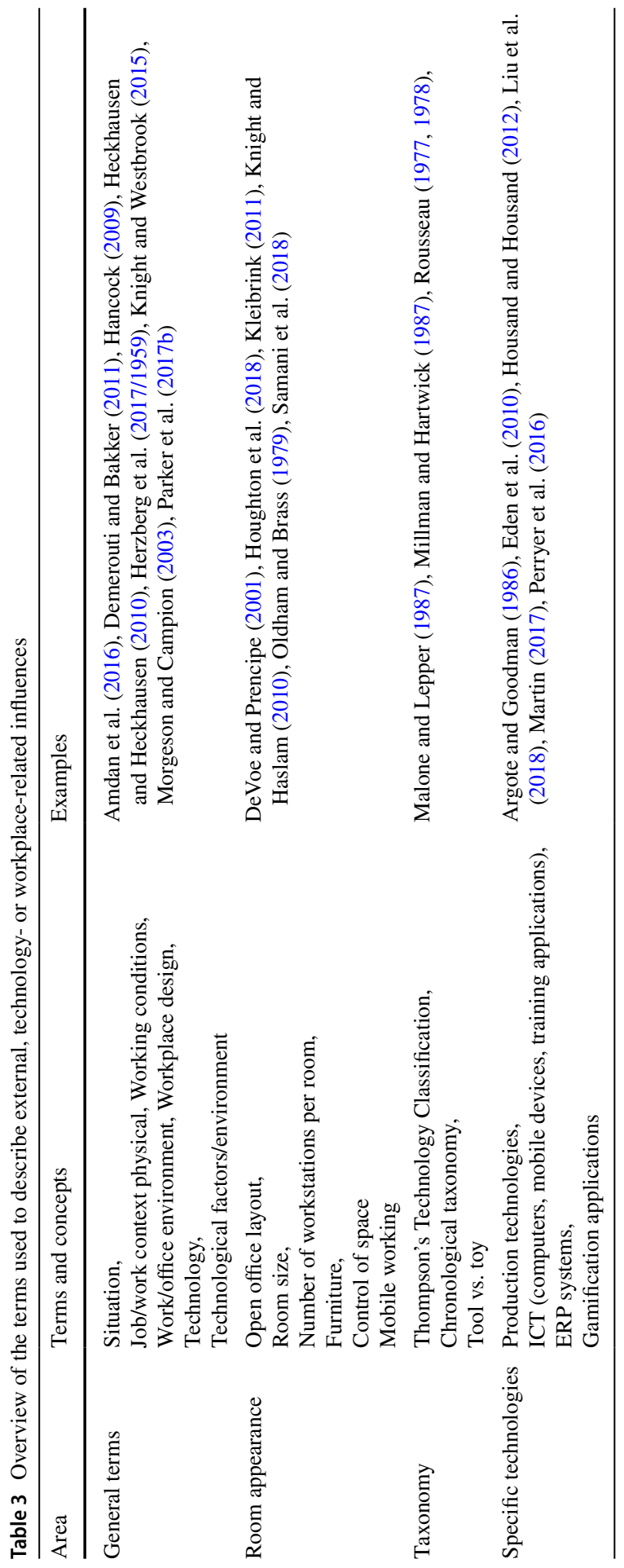


represent a rather general understanding including — but not focusing on-workplace technologies.

Other authors narrow down their understanding: Technology (Amabile 1993; Methot and Phillips-Grant 1998; Morgeson and Campion 2003; Parker and Ohly 2008), technological factors (Das 1999; Parker et al. 2017b), or technological environment (Jong 1989) are the terms used. Again, these publications do not explain their meaning any further or provide specific classification. This lack of definition can be vexing; however, as most of these publications are reviews or theory-building papers, there is no imminent need for operationalization.

Room appearance and layout: A popular approach for taking workplace technologies into account is observing reactions to office layout and equipment. While these technologies do not directly generate added value, they are an integral part of the workplace. One of the earlier examples is the research by Oldham and Brass (1979). They observed employees' reactions after moving into an open office layout. Greenberg (1988), DeVoe and Prencipe (2001), and Lawrence and Nohria (2002) also focused on workplace technologies incorporated in workplace design, such as room size or furniture. Miller et al. (2001) chose a very specific approach and examined how the 'sense of place' influences motivation. As the perception of the physical environment differs, this concept may well hold explanatory power for how workplace technology affects workers in different ways. In a survey, they collected data on physical comfort, the perception of objects, furniture, and other environmental aspects (= sense of place). Their findings suggest a significant positive correlation between sense of place and motivation.

Samani et al. (2018) conducted a survey on the effects of transforming an open space layout by adding partitions. Their results show increased satisfaction and motivation. The new individual workstations offered the opportunity for workers to adjust their surroundings to their individual needs to a certain degree, e.g. the level of lighting. A similar approach was chosen by Knight and Haslam (2010). In their survey, they focused on managerial control of office space. Other researchers evaluate office layout or changing environments due to flexible work models. Research includes details on single office, multi office, or open space layouts (Kleibrink 2011) as well as interactive concepts like coworking spaces (Houghton et al. 2018). Olson and Tasley (1983) and Janneck et al. (2018) also included other working concepts, like home office or mobile working (= hoteling). These approaches are particularly popular in the research areas of facility and real estate management. They reflect the office trends shifting away from the individual office to open solutions with tele- and virtual working. While this approach is specific and comprehensive at the same time, details on technological tools and characteristics are lacking.

One possibility for ensuring both a comprehensive understanding of and a focus on technological aspects of the workplace is to classify them in a taxonomy. Rousseau (1977, 1978), for example, applies James D Thompson's technological classification scheme from 1967 that distinguishes between long-linked, mediated, and intensive technologies. Long-linked technologies describe a structured system with clear cause-and-effect-relationships. They are characterized by highly standardized sequential processes like an assembly line. Mediated technologies 
still contain prescribed processes; however, the tool to be applied must be chosen individually by the employee. With current technological advances, intensive technologies are on the rise. Here, the result of processes is not clear, and the appropriate technology has to be chosen individually (Thompson 1967). These systems are mainly found in jobs with creative tasks and human interaction, which are gaining in importance during the digital transformation (Frey and Osborne 2017).

In their survey on employees' responses to environmental structures, Pierce et al. (1984) took a similar stance. To operationalize technology, they adopted a multi-dimensional approach, taking operations technology, material technology, and knowledge technology into account.

Another approach for classifying technology is to do so chronologically. Millman and Hartwick (1987) summarized different early ICT-applications, such as mainframe and personal computers, or teleconferencing, under the term 'office automation.' Cascio and Montealegre (2016) analyze ubiquitous computing (e.g., electronic monitoring systems, robots, teleconferencing, and wearable computing devices) as a further development of enterprise, end-user, and strategic computing.

Malone and Lepper (1987) categorize technologies and activities based specifically on how they influence motivation; they can be tools or toys. While tools are primarily used to achieve an external goal, toys are used for their own sake. The authors use an example to show that this classification is not necessarily distinctive. While most people use their computer to get work done, others take pleasure in mastering this tool (=toy).

Several authors opted for a focused approach and investigated specific technologies. One area worth noting is production technologies. Argote and Goodman (1986), for example, review how individuals react to the introduction of robotics, and Osterloh and Gerhard (1992) discuss the potentials of an anthropocentric production design.

Other research projects focus on applications in the area of information and communication technologies, such as hardware and software tools (Martin 2017; Pacauskas and Rajala 2017; Sidler 1984; Siemens 2005). Lazar et al. (2006), and Eden et al. (2010) examined (stationary) computers in the workplace while the growing mobile access to data plays a major role in a survey undertaken by Sinha and Arora (2015).

Although Benson and Dundis (2003) use the rather general term "technology" in their analysis, they discuss the specific implementation of ICT in nursing trainings. Housand and Housand (2012) also focus on training applications-placing emphasis on educational purposes. Other software applications include communication platforms (Brown 2012), enterprise management systems (Bala and Venkatesh 2013), email applications, or access to internet (Martin 2017). The easy and fast access to information due to these tools is mostly the crucial aspect influencing motivation and behavior.

A very young topic in the area of technology and motivation is gamification. It can be defined "as the use of game design elements in non-game contexts" (Deterding et al. 2011). This innovation deserves special mention as software 
applications and systems are designed using gamification elements specifically to motivate. The combination of rewards, collaboration, and competitive setting is crucial (Domínguez et al. 2013; Janneck et al. 2018; Liu et al. 2018; Perryer et al. 2016).

\subsection{Types of relationships between technology and motivation}

Ten publications adhere to Herzberg's view on work conditions as a hygiene factor (Herzberg et al. 2017/1959). This paradigm highlights the constraining characteristics of workplace technologies. As these design elements and technological applications change over time, the original empirical results are called into question (Siemens 2005). Therefore, Knight and Westbrook (2015) reproduced Herzberg's critical incidents method with data from telecommuters. Their results mainly correspond to those of Herzberg; however, communication and flexibility enabled by ICT became motivators highlighting the role of technology.

Other researchers follow the perspective of this model by viewing external aspects as restricting motivation and performance (Demerouti and Bakker 2011; Karasek 1979). By taking a diary approach, Lazar et al. (2006) examined frustrating effects when using computers. While the authors acknowledge that mild frustration can be motivating, they view most experiences as a problem in the workplace.

Ryan and Deci (2000) evaluate research on the Self-Determination Theory and view motivation as the individual need for growth that inner resources foster. Environmental aspects act as an infrastructure in which demands can cause negative results if too prevalent (Demerouti and Bakker 2011; Karasek 1979; Taylor 2015).

Another 17 publications claim a direct relationship between environmental influences and motivation. Ford (1992) explains the connection as follows: "Because humans are open systems whose existence, functioning, and development depend on material-energy and information exchanges with relevant contexts, the environment is always an integral part of their functioning" (Ford 1992). While the author does not elaborate on the relationship further, other researchers included this aspect in a similar manner. Several authors illustrate the situational (job context) influence on cognitive and motivational processes in their frameworks as an influence equal to the personal disposition/individual inputs (Barford and Hester 2011; Heckhausen and Heckhausen 2010; Houghton et al. 2018; Jong 1989).

While the nature of the relationship (particularly regarding the technological factors) is not described in detail, expectations may play a crucial role (Heckhausen and Heckhausen 2010; Jong 1989; Mitchell 1997; Mitchell and Daniels 2003). Other authors do not provide additional insights on the mechanisms of these processes either, but offer instead more details on the influences investigated. Das (1999), for example, developed a holistic framework describing several factors - technological, among others - that make up work design. Pierce et al. (1984) evaluated environmental structures on different levels (job, technology, work unit, leadership) and how these influence employee behavior (performance, absenteeism, intrinsic motivation, etc.). Results show that job and technology are the most important aspects explaining responses. 
An approach to exploit this direct connection is utilizing workplace technologies as rewards. Perryer et al. (2016), for example, argue that one aspect of gamification applications is extrinsic prizes or badges - depending on the game design - that can be won. Other workplace technologies can also be perceived as a reward. In his survey on equity, Greenberg (1988) distributed status symbols, like remuneration and offices, among sales managers. Here, it is not the functionality of the furniture, but its symbolism that influences perceived fairness and extrinsic motivation (Vilnai-Yavetz et al. 2005). Elsewhere, using technology as rewards is mostly based on managerial recommendations, the scientific value of which is low (DeVoe and Prencipe 2001; O’Donovan 2002; Sidler 1984).

Miller et al.'s (2001) empirical findings suggest a significant positive correlation between sense of place and motivation. Interestingly, it seems that it is not the examined environmental aspects themselves that are the contributor to motivation, but the opportunity to control them. Personalization of furnishings and positioning of objects seem to be particularly important here. This hints towards a rather indirect relationship - researchers in 39 publications describe such mechanisms. In this perspective, some factors act as mediators between the external influence and the motivational processes. Depending on the conceptual framework, these mediators range from emotional aspects and needs to job characteristics. Table 4 provides an overview of the mediators with underlying frameworks and examples. To ensure a structured presentation of the mediators and allow for readability, we numbered each item in both the table and in the text. The numbers do not represent a ranking.

Perhaps the most obvious understanding of the indirect influence of technologies is that they can satisfy needs (1). Osteraker (1999), for example, claims that physical working conditions address physical needs. Other examples of needs include safety, esteem, self-actualization (Maslow and Stephens 2000), social interaction (Brown 2012; Lawrence and Nohria 2002), or the need to succeed (Nohria et al. 2008; Perryer et al. 2016; Sinha and Arora 2015). Brenner (1999) and Benson and Dundis (2003) provide a very clear and holistic perspective on how technology contributes to need satisfaction. They discuss the effects of workplace design elements, ICT, and training on employees in offices and the healthcare sector on every level of Maslow's Need Hierarchy. They argue for example, that technology applied in training situations can provide the feeling of (job) security and the application of ICT enhance belonging to groups regardless of the person's current location.

A wide array of publications - in fact the whole ergonomics research streamdeal with workplace technologies and how they affect the human body. As the focus here is anatomy, cognitive and affective outcomes-like work motivation-are mainly neglected. Paul (1997) provides an exception. He connects workplace design (including office equipment) with the notion that it can have pampering effects on need satisfaction - both on the human body and motivation. He assumes an inverted U-shaped correlation with productivity and employee motivation. The implication would be that a physically uncomfortable workplace design leads to dissatisfaction (which would be in line with the Herzberg's findings), while a too 'plushy' workplace leads to employees feeling too comfortable and even lazy.

Another approach is to focus on the characteristics of the workplace rather than individual needs. Soon after Hackman and Oldham published the Job Characteristics 


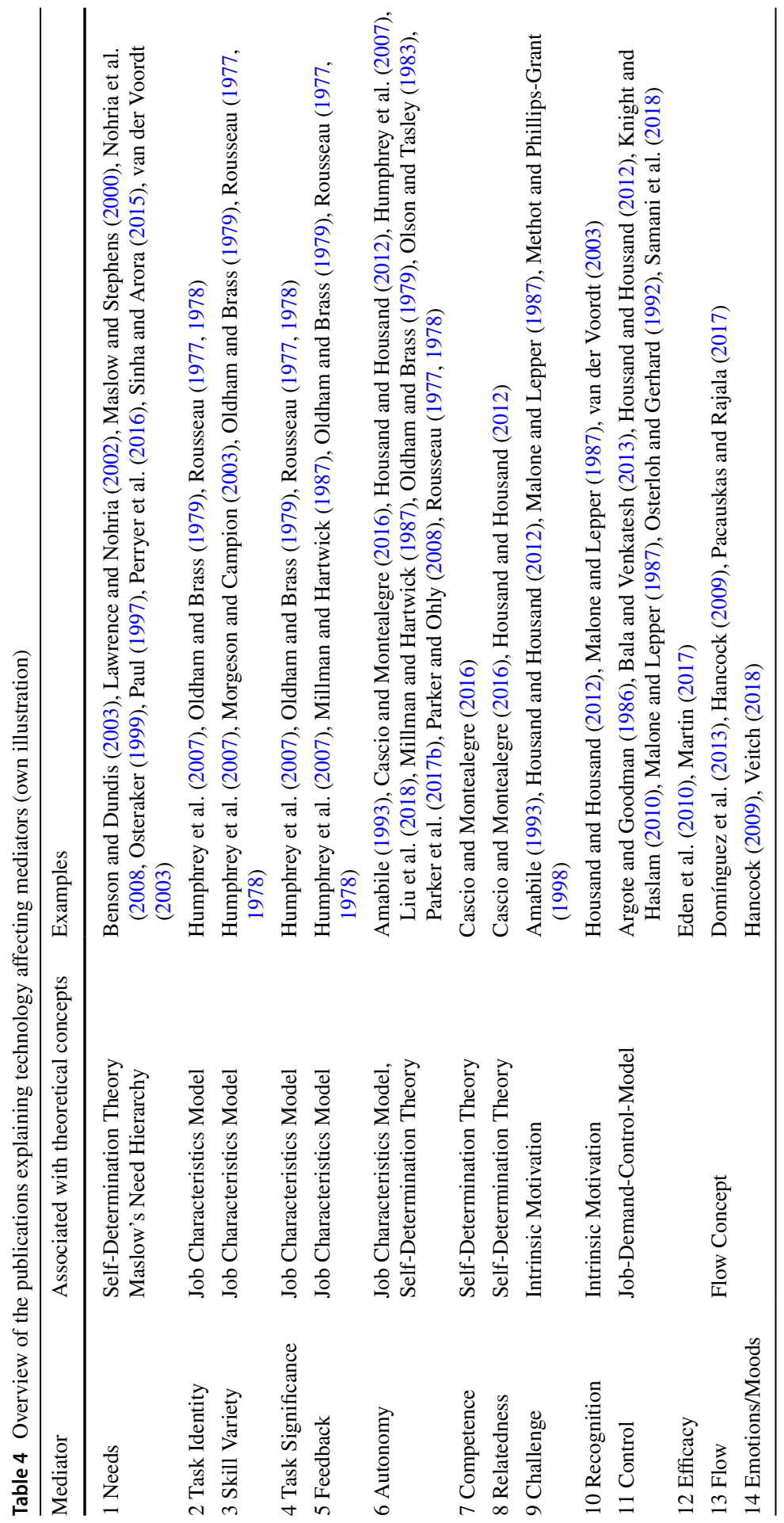


Model, Denise M Rousseau analyzed the Job Characteristics (2 Task Identity, 3 Skill Variety, 4 Task Significance, 5 Feedback, 6 Autonomy) and how they interact with the (technological) environment (Rousseau 1977, 1978). She found that the design of processes and technology use is correlated with Job Characteristics as well as with behavioral and attitudinal outcomes. At the same time, Oldham and Brass (1979) evaluated the internal motivation of office employees after moving from cellular to open offices. A sharp decline in motivation can be explained by a drop in the Job Characteristics.

Other authors argue that the Job Characteristics can be shaped by technologies: It is easy to agree with the claim that "autonomy originates in the workplace rather than the job" (Karanika-Murray and Michaelides 2015) when imagining that (mobile) access to data provides employees with the power to decide where and when to work (Millman and Hartwick 1987; Olson and Tasley 1983). In their experiment with CNC machine operators, Liu et al. (2018) designed a gamified approach to influence Skill Variety, Feedback, and Autonomy for workers. An app provides points and badges for achievements in different challenges. The data on 80 participants in total reveal a significant increase in motivation and job satisfaction.

To motivate employees, Cascio and Montealegre (2016) recommend implementing technologies addressing the needs for autonomy (6), competence (7), and relatedness (8) based on the Self Determination Theory. While physical design decisions can influence perceived relatedness, virtual technologies can also contribute to satisfying social needs. Housand and Housand (2012) suggest mentoring networks and online group tasks to promote cooperation.

In their Expanded Work Design Model based on the JCM, Humphrey et al. (2007) conducted a meta-analysis with 259 studies and 219,625 participants. While there were not enough studies available to make valid claims on the effects of work context characteristics on motivation, a positive effect of both work conditions and ergonomics on attitudinal outcomes and a negative effect of physical demand on behavioral outcomes can be assumed (Humphrey et al. 2007) — this finding is in line with the publications we subsumed under the "technology as a hygiene factor" section. While physical demand in the form of insufficient and complicated workplace design demotivates employees, work needs to be challenging to a certain extent to motivate (Amabile 1993; Housand and Housand 2012; Malone and Lepper 1987). As too great a challenge or too difficult tasks can cause frustration and unchallenging work can be monotonous, Housand and Housand (2012) point out the opportunities online programs offer for students: gifted students can attend additional classes and solve harder tasks to achieve their optimal level of challenge (9). One of the mechanisms influencing this aspect is whether the technology at hand is associated with increased skill requirements (Methot and Phillips-Grant 1998).

Another mechanism is based on the information technological elements convey (see also technology as a reward). Recognition (10) as a facilitator for motivation is closely connected to feedback (5) and rewards as they can be perceived as symbols of recognition for the performance. Technology can be leveraged to provide recognition, for example, by implementing gamification elements containing achievements, badges, and rewards for individuals (Housand and Housand 2012). The act 
of implementing technologies and placing emphasis on workplace design can also provide recognition (van der Voordt 2003).

The feeling of control (11) over one's individual environment can in fact enhance motivation (Samani et al. 2018) while a lack of control may lead to discomfort and demotivation (Argote and Goodman 1986; Bala and Venkatesh 2013; Knight and Haslam 2010; Osterloh and Gerhard 1992). A close connection to autonomy (6) can be assumed, as Cascio and Montealegre (2016) find: "Autonomy is the need to control one's actions" (p. 356), and Housand and Housand (2012) even analyze the two concepts as one. Organizations can provide this feeling of control by implementing new technology and accompanying processes. For example, when introducing mobile devices, management can increase the autonomy by offering the free choice of where to work.

Technologies in the workplace can also motivate employees by enabling them to do their job. ICT in particular can provide smooth processes and motivate through means efficacy (12) (Eden et al. 2010). Martin's (2017) findings point in a similar direction. She shows that technologies facilitating internal information flow increase employees' introjected regulation and intrinsic motivation. On the other hand, technologies decreasing communication costs (e.g., groupware or intranet) cause negative effects as they provide information access to higher management and make employees feel less empowered.

Yet another approach to understanding motivation is to consider affective aspects. Emotions and other factors play a major role in the flow concept (13) (Csikszentmihalyi 2010). The concept describes a cognitive state of focus and enjoyment, like intrinsic motivation. This state can be facilitated by activities and individual preferences as well as by situational aspects. Veitch (2018), for example, claims that a positive working environment (with regard to lighting and ventilation) can lead to a good mood/pleasure (14) and engages employees with an "intrinsic interest in their work" (Veitch 2018). Easy-to-use technology can also contribute to achieving this state (Domínguez et al. 2013; Hancock 2009; Pacauskas and Rajala 2017). The ease of use is determined by — among other factors - an intuitive interface.

\section{Discussion}

We examined publications from the fields of psychology, management, educational sciences, and facility management. The results from our comprehensive review of the literature show that researchers hold different perspectives on the question of how workplace technologies influence employee motivation.

\subsection{Map of the field}

After reviewing the past research on work motivation and how it takes workplace technology into account, we propose clustering research into four paradigms. While the distinction is not mutually exclusive in all cases, most of the publications can be assigned to at least one of them. 
1. Technology as background music: As described in the process of our literature selection, we find that traditional motivation theories tend to focus on motivation being a result of cognitive processes and individual preferences. Most of the content and process theories can be taken as examples here. Although they promote a person-centered view, situational aspects in general and workplace technologies in particular are mentioned. These researchers acknowledge the influence of these external aspects with varying specification, and some also examine them more closely (Sundstrom 2001; Taylor and Westover 2011; Wong et al. 2008). Yet, in their observations and frameworks, environmental aspects can be compared to background music, i.e., it is there, but in their approaches, technology does not make a difference. While these works were not at the center of our research as they do not focus on technology, it is essential to acknowledge this paradigm as it constitutes a major amount of research.

2. Technology as a hygiene factor: This is a popular paradigm researching the influence of workplace technology by focusing on the negative and health related effects. Mainly considerations based on Herzberg's findings, the Job-DemandsControl-Model, and publications on ergonomics can be found in this paradigm. These publications all share the view that appropriate physical surroundings are necessary to prevent dissatisfaction and illness, but not to motivate (Herzberg et al. 2017/1959). This research was mostly published in scientific journals with an average JCR impact factor of 3.0. While this perspective certainly holds true to a certain extent, both the suspected research artifact of the critical incidents method (Hackman and Oldham 1976) and the emergence of new technologies (Knight and Westbrook 2015) suggest a more complex connection.

3. Technology as a motivator: A number of publications propose a direct (and positive) impact on employee motivation. Offering the latest gadget as an incentive for high performing employees poses a feasible solution for managers; however, these recommendations mostly do not explain which aspects of this approach are crucial, nor do they take the differences between intrinsic and extrinsic motivation into account. Here, mainly managerial recommendations view technology as a potential reward to improve (extrinsic) motivation and employee retention (DeVoe and Prencipe 2001; Houghton et al. 2018; Miller et al. 2001; O'Donovan 2002). Most of these publications are not peer reviewed research and those that are have an average JCR rating of 2.2.

4. Technology as an influencer of mediators: The majority of publications claim an indirect relationship between workplace technology and motivational outcomes. These frameworks mostly build on the Job Characteristics Model, the Self Determination Theory, and needs models (see Table 4). The two Job Characteristics 'Autonomy' and 'Skill Variety,' as well as individual needs are the most frequently mentioned mediators (Schmid and Auburger 2020). Researchers representing this perspective mostly based their assumptions on rigorous data and prior research results, which is also reflected by the average JCR rating of 5.0 for these articles. The consideration of a mediating factor can explain some of the complex structures of motivation; however, research does not (yet) follow a predominant paradigm regarding the connection between workplace technologies and motivation. 


\subsection{Practical implications}

Regardless of the individual perspective on the topic, when implementing a new workplace technology or rethinking workplace design, management should consider the effects on employee motivation. These can even be addressed strategically (Kim 2014; Mitchell 1997; Schmid 2020). The literature shows that by choosing suitable technology, Job Characteristics, ergonomics, and needs satisfaction can be facilitated to motivate employees and thereby increase productivity, output quality, or achieve other strategically relevant outcomes. As research results are still fragmented and often include overly specific technologies or overly general constructs, it is difficult to make an overall recommendation. Yet, the results show two aspects applicable to most decision situations managers face when it comes to motivating workplace design:

1. Conscious technology implementation: Modern technologies offer great potential for new processes and interactions. Implementing a new tool has various consequences for other organizational features. While the decision for the "right" technology is important, the way it is implemented and perceived is crucial. How these innovations are perceived depends on aspects such as company culture, leadership style, individual skills, etc. We illustrate this consideration using the (previously mentioned) example of mobile devices: Having a smartphone at hand can empower an employee to access work-related information whenever and wherever he or she wants. This increases autonomy and therefore motivation. At the same time, the very same technology also enables managers to monitor their subordinates more closely and can increase the expectancy to be available at any time. This results in a lack of control for the employee and can cause demotivation (Schmid and Auburger 2020). In this case, leadership style mediates the connection between technology and motivation. In addition, the perception of technologies determines whether employees sense opportunities or threats in these innovations (Bala and Venkatesh 2013; Cascio and Montealegre 2016; Parker and Grote 2020). Eden et al. (2010) conceptualized this relationship as 'means efficacy' and showed that believing in the usefulness of a tool can increase efficacy and productivity. For management, this means that these and other aspects need to be considered consciously when implementing new technology or redesigning workplace.

2. Allow employee participation: Depending on the area of work and the individual preferences, every 'ideal' workplace looks different. Including employees in the design process can have various effects. First, they have access to a platform to express their individual needs and help select the workplace technology in a manner that achieves needs satisfaction. Second, by giving them control over design decisions, the design process will become motivating in itself.

Providing endless options to create individual workplace settings will be neither financially nor organizationally feasible. We suggest a predefined range of design features complying with company standards—a cafeteria-style workplace (Becker and Steele 1995).

Miller et al. (2001) show that providing choices—even on small and cost-effective features-can be applied successfully in many cases: choosing and arranging furniture or personalizing one's desk can have a positive effect on motivation. 


\subsection{Agenda for further research}

While this paper provides only a partial examination of the available literature, our structured approach offers a comprehensive picture of existing research. The 67 results show that a person-centered view is still the predominant paradigm. "This is unfortunate, as research in other areas has documented the importance of both the social environment and work context for a wide range of outcomes" (Humphrey et al. 2007). The number of calls for research on a holistic perspective is already on the rise. Drawing on these calls and the results presented, we propose the following research questions for future topics:

\section{How can different types of workplace technologies be classified?}

When collecting research on the effects of workplace technology, different disciplines address the topic from their individual point of view. The result is a variety of terms and concepts attempting to describe the external influences on motivation (see also Table 3). While many authors prefer a general understanding, such as context, situation, or environment, others narrow it down to work-specific terminology, such as workplace, workspace, job/work design, or technology. Almost all these concepts lack a clear and universal understanding.

In this paper, we have already provided a definition of workplace technology. It provides a broad understanding of technology, that is quite suitable for the purpose of this study. However, a taxonomy would offer the opportunity to change the focus of the investigation without changing the terminology. Only a few researchers worked with a clear system that included different technologies based on their functionality or effect. While the approach pursued by Millman and Hartwick (1987) or Cascio and Montealegre (2016) — to classify technology according to its evolution-is intuitively understandable, it focuses on a certain kind of technology and ignores others. In the aforementioned publications, the focus lies on ICT, while production technologies or ergonomic aspects are neglected. On the other hand, James D Thompson's technological classification applied by Rousseau $(1977,1978)$ and Pierce et al. (1984) focuses on the way technology influences processes and tasks. This kind of taxonomy offers the inclusion of various workplace technologies. As the focal point lies on value adding processes, namely ergonomics and real estate, aspects such as office design are not considered.

Providing a comprehensive categorization is challenging, especially at a time when boundaries are blurred and workplace technologies are becoming more diverse than ever before. Yet, achieving this might just be the cornerstone on which to build linking conceptualization.

How do new technologies influence the workplace and therefore affect employee motivation?

Conceptualizing technology influencing mediators seems the most promising perspective of the four schools of thought outlined above. Scholars representing this perspective mostly base their arguments on rigorous research and complex models. However, a holistic framework including both the specifics of workplace technologies and motivational outcomes could help to explain the complex interrelationships. As these concepts are still rare, we recommend combining existing theories and frameworks. Some authors have already made promising advances here. Parker 
and Ohly (2008), Diefendorff and Chandler (2011), Taylor (2015), and Humphrey et al. (2007) propose multi-level frameworks including some workplace design characteristics and individual outcomes. These frameworks offer insights on interdependencies between individual, organizational, and external factors. However, the role of workplace technology remains vague.

The paths between workplace technologies and individual outcomes lack understanding (Parker and Ohly 2008). Therefore, we propose empirical research based on the insights described in this paper. As prior research has been predominantly quantitative and focused on correlations, qualitative approaches like case studies can help to gain a better understanding of causal relationships.

\section{How do moderators affect the relationship between workplace technology and employee motivation?}

Having shown that holistic frameworks are necessary to understand the complex relationship between workplace technology and employee motivation, we would like to emphasize the role of moderators. In our example about the mobile devices, leadership can affect perceptions of the impact workplace technologies have on motivation. This and other organizational aspects have already been examined, such as coworkers or leadership (Amabile and Kramer 2010; Csikszentmihalyi 2010; Karanika-Murray and Michaelides 2015; Maxwell 2008), processes or reward systems (Seeck and Diehl 2016; Wright and Cordery 1999), or organizational climate (Ferris and Gilmore 1984), as well as extrinsic workplace attributes, e.g., pay, job security (Amabile et al. 1986; Deci and Ryan 1985; Taylor and Westover 2011), or tasks (Hackman and Oldham 1976; Luczak et al. 2012; Medsker and Campion 2001). These authors provide insights on the role these organizational factors play regarding employee motivation, whereas most of the research excludes workplace technologies.

Other potential moderators might be socioeconomic or cultural aspects. Some authors assume that the relationship between workplace technology and motivation is determined by age. Based on empirical data on more than 3000 managers and professionals, Wong et al. (2008) identified age-related differences in motivational drivers. Members of the generations $\mathrm{X}$ and $\mathrm{Y}$ were found to be more motivated by progression and an affiliative workplace than Baby Boomers. Barford and Hester (2011) support these findings. Moreover, work environment demonstrates a higher overall relevance (after compensation) for the younger employees (Rožman et al. 2017). One of the reasons for this might be that the ease in handling technology and the accompanying high speed of communication make the younger generations seem more demanding. Kanfer and Ackerman (2004) argue in a similar manner: "The differences in work motivation as adults age pertain mainly to the impact of age-related changes in competencies and motives on motivational-processing components." Being confronted with new technology can therefore cause a dissonance between competences and demands, which might lead to behavior aimed at protecting self-concept rather than progression in later stages of life (Kanfer and Ackerman 2004). As these insights are mainly assumptions at this stage, further research on this topic seems both interesting and necessary. 


\section{Which aspects of new technology influence the individual work organization and how?}

As outlined above, existing research discusses either vague concepts of workplace design elements or the effects of specific technologies. These mostly include office design and ICT applications. The motivational impact of other upcoming technologies lacks scientific understanding and offers a wide field of research opportunities: production technologies like automation systems or robotics as well as promising applications of artificial intelligence, like voice recognition systems, personal virtual assistants, or virtual/augmented reality applications. We believe that these technological trends have unprecedented qualities. In the era of 'Industrie 4.0' and 'Made in China 2025,' everything is connected and technology is ubiquitous (Brynjolfsson and McAfee 2016; Cascio and Montealegre 2016; Parker and Grote 2020). While this leads to a significant increase in collaborative types of work, these new technologies allow greater opportunities for individualization and autonomous work organization as well (Brown et al. 2017). The amount and velocity of new skills needed is greater than ever before (Frey and Osborne 2017; Koetsier 2018; Leopold et al. 2016). To understand these technologies and how their characteristics affect work motivation, we suggest further research. Empirical data on different use cases is necessary.

\section{Conclusions}

In this paper, we developed a research agenda to include workplace technology in motivation research. No matter how workplace technologies are defined, many researchers emphasize the need for individualization. What one employee perceives as the optimal workplace design might be perceived as dissatisfying to another. The person-environment fit plays a major role (Samani et al. 2018). The toys vs. tools approach from Malone and Lepper (1987) and research on the 'sense of place' (Miller et al. 2001) shows how technologies can be perceived individually and help to explain different effects on employees. Current and future technologies provide individualized solutions and applications, and therefore the opportunity to address individual needs and motivation in the workplace. The advances in robotics, ICT, and artificial intelligence can pave the way towards motivational workplace design, instead of acting only as a restriction to change processes and job characteristics (Daugherty and Wilson 2018).

The highly volatile job market and fast changing environment pose increasing uncertainty for individuals and a need for lifelong education. With creative tasks and knowledge-based jobs on the rise, creativity emerges as an essential requirement-employees need to be highly intrinsically motivated to meet these requirements (Amabile et al. 1986). Creating a motivating workplace can be a sustainable investment for a company's decision maker. Whereas further research is needed, it is not necessarily the physical environment in itself that might be the motivating factor, but the way it is perceived and the power to influence it (Brill et al. 1984; Knight and Haslam 2010) as well as the way it shapes job characteristics and addresses needs (van der Voordt 2003). Both researchers and managers need to take these 
aspects into account to generate fruitful research and sustainable workplace strategies. Workplace technology needs to be more than just background music in the future.

Acknowledgements We wish to thank various people for their contribution to this project; Steffi Steinhauser and Julia Oehler for their encouragement and persistent help. Special thanks should be given to Suzanne Weinberger and the reviewer for their useful and constructive recommendations on this project.

Funding Open Access funding enabled and organized by Projekt DEAL.

\section{Compliance with ethical standards}

Conflict of interest Not applicable.

Availability of data and material All relevant data is included in the manuscript, a detailed audit trail and list of literature is available upon request.

Code availability Not applicable.

Open Access This article is licensed under a Creative Commons Attribution 4.0 International License, which permits use, sharing, adaptation, distribution and reproduction in any medium or format, as long as you give appropriate credit to the original author(s) and the source, provide a link to the Creative Commons licence, and indicate if changes were made. The images or other third party material in this article are included in the article's Creative Commons licence, unless indicated otherwise in a credit line to the material. If material is not included in the article's Creative Commons licence and your intended use is not permitted by statutory regulation or exceeds the permitted use, you will need to obtain permission directly from the copyright holder. To view a copy of this licence, visit http://creativecommons.org/licen ses/by/4.0/.

\section{References}

Amabile TM (1993) Motivational synergy: toward new conceptualizations of intrinsic and extrinsic motivation in the workplace. Hum Resour Manag Rev 3:185-201

Amabile TM, Kramer SJ (2010) What really motivates workers: understanding the power of progress. Harv Bus Rev 88:44-45

Amabile TM, Hennessey BA, Grossman BS (1986) Social influences on creativity: the effects of contracted-for reward. J Pers Soc Psychol 90:14-23

Amdan S, Rahman RA, Shahid SAM, Bakar SA, Khir MM, Demong NAR (2016) The role of extrinsic motivation on the relationship between office environment and organisational commitment. Proc Econ Fin 37:164-169. https://doi.org/10.1016/S2212-5671(16)30108-3

Argote L, Goodman PS (1986) The organizational implications of robotics. In: Davis DD (ed) Managing technological innovation. Jossey-Bass, San Francisco, pp 127-153

Bala H, Venkatesh V (2013) Changes in employees job characteristics during an enterprise system implementation: a latent growth modeling perspective. MIS Q 37:1113-1140

Barford IN, Hester PT (2011) Analysis of Generation Y Workforce Motivation Using Multiattribute Utility Theory, Fort Belvoir

Barrett S (2015) How can the workplace motivate staff? https://www.employeebenefits.co.uk/issues/ motivation-and-recognition-supplement-2015/how-can-the-workplace-motivate-staff/. Accessed 10 October 2020

Becker FD, Steele F (1995) Workplace by design: mapping the high-performance workscape, 1st edn. Jossey-Bass, San Francisco

Benson SG, Dundis SP (2003) Understanding and motivating health care employees: integrating Maslow's hierarchy of needs, training and technology. J Nurs Manag 11:315-320 
Billings RS, Klimoski RJ, Breaugh JA (1977) The impact of a change in technology on job characteristics: a quasi-experiment. Adm Sci Q 22:318-339

Bouncken RB, Gast J, Kraus S, Bogers M (2015) Coopetition: a systematic review, synthesis, and future research directions. Rev Manag Sci 9:577-601. https://doi.org/10.1007/s11846-015-0168-6

Brenner P (1999) Motivating knowledge workers: the role of the workplace. Qual Prog 32:33-37

Brill M, Margulis ST, Konar E (1984) Using office design to increase productivity. Workplace Design, Buffalo, NY

Brown T (2012) Influence of technology and the effects on one's interpersonal relationships in the workplace. http://customwritingtips.com/component/k2/item/11789-influence-of-technology-and-theeffects-on-one $\%$ E2\% $80 \% 99$ s-interpersonal-relationships-in-the-workplace.html?tmpl=compo nent\&print $=1$. Accessed 7 June 2018

Brown J, Gosling T, Sethi B, Sheppard B, Stubbings C, Sviokla J, Williams J, Zarubina D (2017) Workforce of the future: The competing forces shaping 2030. https://www.pwc.com/gx/en/services/ people-organisation/publications/workforce-of-the-future.html. Accessed 1 Nov 2020

Brynjolfsson E, McAfee A (2016) The second machine age: Wie die nächste digitale Revolution unser aller Leben verändern wird, 6. Auflage. Börsenmedien, Kulmbach

Caramela S (2018) A workplace that works: designing a productive office. https://www.businessnewsdai ly.com/7456-workspace-design-productivity.html.

Cascio WF, Montealegre R (2016) How technology is changing work and organizations. Annu Rev Organ Psych Organ Behav 3:349-375. https://doi.org/10.1146/annurev-orgpsych-041015-062352

Chan JK, Beckman SL, Lawrence PG (2007) Workplace design: a new managerial imperative. Calif Manag Rev 49:6-22

Csikszentmihalyi M (2010) Flow: Das Geheimnis des Glücks, 15. Aufl. Klett-Cotta, Stuttgart

Das B (1999) Development of a comprehensive industrial work design model. Hum Factors Ergon Manuf 9:393-411. https://doi.org/10.1002/(SICI)1520-6564(199923)9:4<393:AID-HFM6>3.0.CO;2-D

Daugherty PR, Wilson HJ (2018) Human + machine: reimagining work in the age of AI. Harvard Business Review Press, La Vergne

Dell Technologies, Intel (2016) Future Workforce Study. https://i.dell.com/sites/csdocuments/Business_ solutions_whitepapers_Documents/de/de/dell_intel_future_workforce-study.pdf. Accessed 1 Nov 2020

de Jong JR (1989) The management of work and effort. In: Wild R (ed) International handbook of production and operations management. Cassell, London, pp 584-599

Deci EL, Ryan RM (1985) Intrinsic motivation and self-determination in human behavior. Perspectives in social psychology. Plenum Press, New York, NY

Deci EL, Koestner R, Ryan RM (1999) A meta-analytic review of experiments examining the effects of extrinsic rewards on intrinsic motivation. Psychol Bull 125:627-668. https://doi. org/10.1037//0033-2909.125.6.627

Demerouti E, Bakker AB (2011) The Job Demands-Resources model: challenges for future research. SA J Ind Psychol 37:a974. https://doi.org/10.4102/sajip.v37i2.974

Deterding S, Dixon D, Khaled R, Nacke LE (2011) From game design elements to gamefulness: defining "Gamification". In: Proceedings of the 15th international academic MindTrek conference envisioning future media environments. ACM, New York, NY, pp 9-15

DeVoe D, Prencipe LW (2001) Mastering motivation: in the midst of economic and emotional volatility, managers can take action to boost staff morale. InfoWorld 23:42-43

Diefendorff JM, Chandler MM (2011) Motivating employees. In: Zedeck S (ed) APA handbook of industrial and organizational psychology, Volume 3: Maintaining, expanding, and contracting the organization, 1st edn. American Psychological Association, Washington, DC, pp 65-137

Domínguez A, Saenz de Navarrete J, de Marcos L, Fernández-Sanz L, Pagés C, Martínez-Herráiz J-J (2013) Gamifying learning experiences: practical implications and outcomes. Comput Educ 63:380-392. https://doi.org/10.1016/j.compedu.2012.12.020

Eden D, Ganzach Y, Flumin-Granat R, Zigman T (2010) Augmenting means efficacy to boost performance: two field experiments. J Manag 36:687-713. https://doi.org/10.1177/0149206308321553

Eventboard.io (2016) You can't buy workplace happiness: but tech helps. http://pages.teem.com/rs/379VML-039/images/Workplace-Happiness-Infographic-600px.jpg. Accessed 6 March 2019

Ferris GR, Gilmore DC (1984) The moderating role of work context in job design research: a test of competing models. Acad Manag J 27:885-892

Fisch C, Block J (2018) Six tips for your (systematic) literature review in business and management research. Manag Rev Q 68:103-106. https://doi.org/10.1007/s11301-018-0142-x 
Ford ME (1992) Motivating humans: goals, emotions, and personal agency beliefs. SAGE, Newbury Park, CA

Frey CB, Osborne MA (2017) The future of employment: how susceptible are jobs to computerisation? Technol Forecast Soc Chang 114:254-280. https://doi.org/10.1016/j.techfore.2016.08.019

Greenberg J (1988) Equity and workplace status: a field experiment. J Appl Psychol 73:606-613

Hackman RJ, Oldham GR (1976) Motivation through the design of work: test of a theory. Organ Behav Hum Perform 16:250-279

Hancock PA (2009) Mind, machine and morality: toward a philosophy of human-technology symbiosis. CRC Press, Boca Raton

Hartog L, Weijs-Perrée M, Appel-Meulenbroek R (2017) The influence of personality on user satisfaction: multi-tenant offices. Build Res Inf 46:402-416. https://doi.org/10.1080/09613218.2017.13070 15

Heckhausen J, Heckhausen H (2010) Motivation und Handeln, 4., überarbeitete und erweiterte Auflage. Springer-Lehrbuch. Springer, Berlin

Herzberg F, Mausner B, Snyderman BB (2017/1959) The motivation to work. Routledge Taylor \& Francis Group, London

Houghton KR, Foth M, Hearn G (2018) Working from the other office: trialling co-working spaces for public servants. Aust J Public Adm 77:757-778. https://doi.org/10.1111/1467-8500.12317

Housand BC, Housand AM (2012) The role of technology in gifted students' motivation. Psychol Sch 49:706-715. https://doi.org/10.1002/pits.21629

Humphrey SE, Nahrgang JD, Morgeson FP (2007) Integrating motivational, social, and contextual work design features: a meta-analytic summary and theoretical extension of the work design literature. J Appl Psychol 92:1332-1356. https://doi.org/10.1037/0021-9010.92.5.1332

Janneck M, Jent S, Weber P, Nissen H (2018) Ergonomics to go: designing the mobile workspace. Int J Human Comput Interact 34:1052-1062. https://doi.org/10.1080/10447318.2017.1413057

Kampschroer K, Heerwagen JH (2005) The strategic workplace: development and evaluation. Build Res Inf 33:326-337. https://doi.org/10.1080/09613210500161976

Kanfer R, Ackerman PL (2004) Aging, adult development, and work motivation. Acad Manag Rev 29:440-458

Karanika-Murray M, Michaelides G (2015) Workplace design. J Org Eff People Perform 2:224-243. https://doi.org/10.1108/JOEPP-08-2014-0048

Karasek RA (1979) Job demands, job decision latitude, and mental strain. Adm Sci Q 24:285-308

Kim SE (2014) Physical workplace as a strategic asset for improving performance in public organizations. Admin Soc 46:496-518. https://doi.org/10.1177/0095399713479104

Kleibrink M (2011) Die Welt der Büroarbeit im Wandel - Nutzungsstrategien und Wahlfreiheiten. In: Schittich C (ed) Arbeitswelten. De Gruyter, München, pp 10-17

Knight C, Haslam SA (2010) Your place or mine?: Organizational identification and comfort as mediators of relationships between the managerial control of workspace and employees' satisfaction and well-being. Br J Manag 21:717-735. https://doi.org/10.1111/j.1467-8551.2009.00683.x

Knight PJ, Westbrook J (2015) Comparing employees in traditional job structures vs telecommuting jobs using Herzberg's hygienes \& motivators. Eng Manag J 11:15-20. https://doi.org/10.1080/10429 247.1999.11415014

Koetsier J (2018) Why Robots won't kill jobs: the world's largest robotics company says more robots means more jobs. https://www.forbes.com/sites/johnkoetsier/2018/03/28/why-robots-wont-killjobs-the-worlds-largest-robotics-company-says-more-robots-means-more-jobs/2/\#6148dcf672b6. Accessed 10 October 2020

Komlosy A (2014) Arbeit: Eine globalhistorische Perspektive; 13. bis 21. Jahrhundert. Promedia, Wien

Krejcie RV, Morgan DW (1970) Determining sample size for research activities. Educ Psychol Meas 30:607-610. https://doi.org/10.1177/001316447003000308

Landsberger HA (1968) Hawthorne revisited: management and the Worker, ist critics, and developments in human relations in industry, third printing. W.F. Humphrey Press, New York

Lawrence PR, Nohria N (2002) Driven: how human nature shapes our choices. Jossey-Bass, San Francisco

Lazar J, Jones A, Shneiderman B (2006) Workplace user frustration with computers: an exploratory investigation of the causes and severity. Behav Inform Technol 25:239-251. https://doi. org/10.1080/01449290500196963

Leopold TA, Ratcheva V, Zahidi S (2016) The Future of Jobs: Employment, Skills and Workforce Strategy for the Forth Industrial Revolution, Geneva 
Liu M, Huang Y, Zhang D (2018) Gamification's impact on manufacturing: enhancing job motivation, satisfaction and operational performance with smartphone-based gamified job design. Hum Factors Ergon Manuf 28:38-51. https://doi.org/10.1002/hfm.20723

Luczak H, Kabel T, Licht T (2012) Task design and motivation. In: Salvendy G (ed) Handbook of human factors and ergonomics, 4th edn. Wiley, Hoboken, NJ, pp 397-440

Malone TW, Lepper MR (1987) Making learning fun: a taxonomy of intrinsic motivations for learning. In: Snow RE, Farr MJ (eds) Aptitude, learning, and instruction: Vol 3. Conative and affective process analyses. Erlbaum, Hillsdale, NJ, pp 223-253

Martin L (2017) Do innovative work practices and use of information and communication technologies motivate employees? Ind Relat J Econ Soc 56:263-292. https://doi.org/10.1111/irel.12173

Maslow AH, Stephens DC (eds) (2000) The Maslow business reader. Wiley, New York

Maxwell JR (2008) Work system design to improve the economic performance of the firm. Bus Process Manag J 14:432-446. https://doi.org/10.1108/14637150810876715

Mayo E (1949) Probleme industrieller Arbeitsbedingungen. Verlag der Frankfurter Hefte, Frankfurt a.M

Medsker GJ, Campion MA (2001) Job and team design. In: Salvendy G (ed) Handbook of industrial engineering: technology and operations management, 3rd edn. Wiley, New York

Methot LL, Phillips-Grant K (1998) Technological advances in the Canadian workplace: an I-O perspective. Can Psychol 39:134-141

Miller NG, Erickson A, Yust BL (2001) Sense of place in the workplace: the relationship between personal objects and job satisfaction and motivation. J Inter Des 27:35-44

Millman Z, Hartwick J (1987) The impact of automated office systems on middle managers and their work. MIS Q 11:479. https://doi.org/10.2307/248977

Mitchell TR (1997) Matching motivational strategies with organizational contexts. Res Organ Behav 19:57-94

Mitchell TR, Daniels D (2003) Motivation. In: Borman WC, Ilgen DR, Klimoski RJ (eds) Industrial and organizational psychology. Wiley, Hoboken, NJ, pp 225-254

Morgeson FP, Campion MA (2003) Work design. In: Borman WC, Ilgen DR, Klimoski RJ (eds) Industrial and organizational psychology. Wiley, Hoboken, NJ, pp 423-452

Nohria N, Groysberg B, Lee L-E (2008) Employee motivation: a powerful new model. Harv Bus Rev $86: 78-84$

O’Donovan D (2002) Interest pays dividends. Employee benefits

Oldham GR, Brass DJ (1979) Employee reactions to an open-plan office: a naturally occurring quasiexperiment. Adm Sci Q 24:267-284

Oldham GR, Hackman RJ (2010) Not what it was and not what it will be: the future of job design research. J Organ Behav 31:463-479. https://doi.org/10.1002/job.678

Olson MH, Tasley R (eds) (1983) Telecommunications and the changing definition of the workplace. Working paper series stern \#IS-83-5d1

Onwuegbuzie AJ, Frels R (2016) 7 steps to a comprehensive literature review: a multimodal \& cultural approach. SAGE, Los Angeles

Osteraker MC (1999) Measuring motivation in a learning organization. J Work Learn 11:73-77. https:// doi.org/10.1108/13665629910260798

Osterloh M, Gerhard B (1992) Neue Technologien, Arbeitsanforderungen und Aufgabenorientierung: Zum Verhältnis von intrinsischer und extrinsischer Motivation. In: Lattmann C, Probst GJB, Tapernoux F, Norek C, Siemers SHA (eds) Die Förderung der Leistungsbereitschaft des Mitarbeiters als Aufgabe der Unternehmensführung: Festschrift für Herrn Prof. Dr. Gaston Cuendet aus Anlaß seines 70. Geburtstages. Physica-Verlag HD, Heidelberg, pp 117-134

Pacauskas D, Rajala R (2017) Information system users' creativity. Inf Technol People 30:81-116. https ://doi.org/10.1108/ITP-04-2015-0090

Parker SK (2014) Beyond motivation: job and work design for development, health, ambidexterity, and more. Annu Rev Psychol 65:661-691

Parker SK, Grote G (2020) Automation, algorithms, and beyond: why work design matters more than ever in a digital world. Appl Psychol 0:1-45. https://doi.org/10.1111/apps.12241

Parker SK, Ohly S (2008) Designing motivating jobs: an expanded framework for linking work characteristics and motivation. In: Kanfer R, Chen G, Pritchard RD (eds) Work motivation: past, present and future. Taylor and Francis, Abingdon, Oxon, pp 234-271

Parker SK, Morgeson FP, Johns G (2017a) One hundred years of work design research: looking back and looking forward. J Appl Psychol 102:403-420. https://doi.org/10.1037/ap10000106 
Parker SK, van den Broeck A, Holman D (2017b) Work design influences: a synthesis of multi-level factors that affect the design of work. Acad Manag Ann 11:267-308

Paul RD (1997) Nurturing and pampering paradigm for office ergonomics. Proceedings of the human factors and ergonomics society 41st annual meeting, pp 519-523

Perryer C, Celestine NA, Scott-Ladd B, Leighton C (2016) Enhancing workplace motivation through gamification: transferrable lessons from pedagogy. Int J Manag Educ 14:327-335. https://doi. org/10.1016/j.ijme.2016.07.001

Pierce JL, Dunham RB, Cummings LL (1984) Sources of environmental structuring and participant responses. Organ Behav Hum Perform 33:214-242

Prince R (2017) Workspace design for your sake. https://www.goalcast.com/2017/02/24/workspace-desig n-sake/.

Rousseau DM (1977) Technological differences in job characteristics, employee satisfaction, and motivation: a synthesis of job design research and sociotechnical systems theory. Organ Behav Hum Perform 19:18-42

Rousseau DM (1978) Characteristics of departments, positions, and individuals: contexts for attitudes and behavior. Adm Sci Q 23:521-540

Rožman M, Treven S, Čančer V (2017) Motivation and satisfaction of employees in the workplace. Bus Syst Res J 8:14-25. https://doi.org/10.1515/bsrj-2017-0013

Ryan RM, Deci EL (2000) Self-determination theory and the facilitation of intrinsic motivation, social development, and well-being. Am Psychol 55:68-78. https://doi.org/10.1037//0003-066X.55.1.68

Samani SA, Eskandari A, Zadeh FO, Samani JE (2018) The impact of environmental design on employee performance at PNPI Group. Glob Bus Organ Excell 37:41-48. https://doi.org/10.1002/joe.21841

Schmid Y (2020) Workplace design as a strategic resource - a qualitative study. Int J Strateg Manag 20

Schmid Y, Auburger J (2020) Implementing workplace technologies - a motivation-oriented approach. In: Ahram T, Taiar R, Colson S, Choplin A (eds) Human Interaction and Emerging Technologies: Proceedings of the 1st International Conference on Human Interaction and Emerging Technologies (IHIET 2019), August 22-24, 2019, Nice, France, 1st ed. 2020. Springer, Cham (CH), pp 53-58

Seeck H, Diehl M-R (2016) A literature review on HRM and innovation - taking stock and future directions. Int J Hum Resour Manag 28:913-944. https://doi.org/10.1080/09585192.2016.1143862

Sidler MP (1984) High tech as a motivating force. People Technol 11

Siemens L (2005) Motivation in a global economy: lessons from Herzberg. Can Public Adm 48:413-418

Sinha N, Arora P (2015) Effects of growing mobile usage at workplace and its impact on work productivity - a detailed analysis. Glob J Res Bus Manag 2:82-91

Sundstrom E (2001) Workplace environmental psychology. In: Smelser NJ (ed) International encyclopedia of the social \& behavioral sciences, pp 16593-16598

Taylor BM (2015) The integrated dynamics of motivation and performance in the workplace. Perform Improv 54:28-37. https://doi.org/10.1002/pfi.21481

Taylor J, Westover JH (2011) Job satisfaction in the public service. Public Manag Rev 13:731-751. https ://doi.org/10.1080/14719037.2010.532959

Thompson JD (1967) Organizations in action: social science bases of administrative theory. McGrawHill, New York

Tranfield D, Denyer D, Smart P (2003) Towards a methodology for developing evidence-informed management knowledge by means of systematic review. Br J Manag 14:207-222. https://doi. org/10.1111/1467-8551.00375

van den Broeck A, Ferris DL, Chang C-H, Rosen CC (2016) A review of self-determination theory's basic psychological needs at work. J Manag 42:1195-1229. https://doi.org/10.1177/0149206316 632058

van der Voordt TJM (2003) Costs and benefits of innovative workplace design. Delft University of Technology, Faculty of Architecture, Dept. of Real Estate and Housing, Delft

Veitch JA (2018) How and why to assess workplace design: facilities management supports human resources. Organ Dyn 47:78-87. https://doi.org/10.1016/j.orgdyn.2018.01.002

Vilnai-Yavetz I, Rafaeli A, Yaacov CS (2005) Instrumentality, aesthetics, and symbolism of office design. Environ Behav 37:533-551. https://doi.org/10.1177/0013916504270695

Vischer JC (2007) The concept of workplace performance and its value to managers. Calif Manag Rev 49:62-79. https://doi.org/10.2307/41166383

Vischer JC (2008) Towards an environmental psychology of workspace: how people are affected by environments for work. Archit Sci Rev 51:97-108. https://doi.org/10.3763/asre.2008.5114 
Wong M, Gardiner E, Lang W, Coulon L (2008) Generational differences in personality and motivation. J Manag Psychol 23:878-890. https://doi.org/10.1108/02683940810904376

Wright BM, Cordery JL (1999) Production uncertainty as a contextual moderator of employee reactions to job design. J Appl Psychol 84:456-463

Publisher's Note Springer Nature remains neutral with regard to jurisdictional claims in published maps and institutional affiliations. 